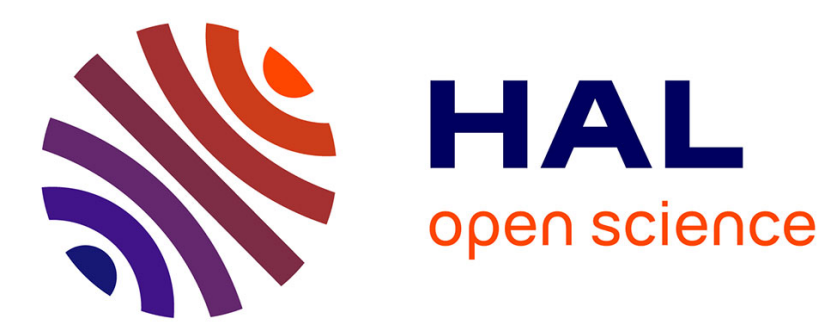

\title{
START ships lipids across interorganelle space
}

Fabien Alpy, Catherine Tomasetto

\section{To cite this version:}

Fabien Alpy, Catherine Tomasetto. START ships lipids across interorganelle space. Biochimie, 2014, 96, pp.85-95. 10.1016/j.biochi.2013.09.015 . hal-03417211

\section{HAL Id: hal-03417211 \\ https://hal.science/hal-03417211}

Submitted on 10 Dec 2021

HAL is a multi-disciplinary open access archive for the deposit and dissemination of scientific research documents, whether they are published or not. The documents may come from teaching and research institutions in France or abroad, or from public or private research centers.
L'archive ouverte pluridisciplinaire HAL, est destinée au dépôt et à la diffusion de documents scientifiques de niveau recherche, publiés ou non, émanant des établissements d'enseignement et de recherche français ou étrangers, des laboratoires publics ou privés. 


\title{
START ships lipids across interorganelle space
}

\author{
Fabien Alpy ${ }^{1 *}$ and Catherine Tomasetto ${ }^{1}$ \\ 1 : Institut de Génétique et de Biologie Moléculaire et Cellulaire (IGBMC), UMR 7104 CNRS/ U964 \\ INSERM/ Université de Strasbourg, BP10142, 67404 Illkirch, C.U. de Strasbourg, France \\ * Corresponding author: E-mail: $\underline{\text { Fabien.Alpy@igbmc.fr }}$
}

\begin{abstract}
The family of StAR related lipid transfer proteins (START) is so-named based on the distinctive capacity for these proteins to transport lipids between membranes. The START domain is a module of about 210 residues, which binds lipids such as glycerolipids, sphingolipids and sterols. This domain has a deep lipidbinding pocket - that shields the hydrophic ligand from the external aqueous environment - covered by a lid. Based on their homology, the fifteen START proteins in mammals have been allocated to six distinct subfamilies, each subfamily being more specialized in the transport and/or sensing of a lipid ligand species. However within the same subgroup, their expression profile and their subcellular localization distinguish them and are critical for their different biological functions. Indeed, START proteins act in a variety of distinct physiological processes, such as lipid transfer between intracellular compartments, lipid metabolism and modulation of signaling events. Mutation or deregulated expression of START proteins is linked to pathological processes, including genetic disorders, autoimmune diseases and cancers. Besides the common single START domain, which is always located at the carboxy-terminal end in mammals, most START proteins harbor additional domains predicted to be critical in favoring lipid exchange. Evidence from well characterized START proteins indicates that these additional domains might be tethering machineries able to bring distinct organelles together and create membrane contact sites prone to lipid exchange via the START domain.
\end{abstract}




\section{Introduction}

Lipids represent a large variety of molecules characterized by their low solubility in water. The major lipids are glycerolipids, sphingolipids and sterols. At the level of the organism, lipids provide multiple functions such as energy sources or hormone mediators. At the cellular level, lipids are structural components of membranes, and they determine the establishment, maintenance and identity of intracellular compartments. Indeed, eukaryotic cells are compartmentalized in discrete organelles which provide the cell with functionally specialized aqueous partitions. They are delimited by membranes that constitute a barrier to the diffusion of soluble signaling molecules or metabolites. Organelles are interdependent units which rely on routes that ensure the exchange of metabolites and information across the cell. By their very nature, lipids require complex modes of transport ensured by both vesicular and non-vesicular mechanisms. Vesicular traffic consists in the formation, transport, docking and fusion of vesicles which transfer lipids between membranes. Non-vesicular transport of lipids occurs by simple desorption of a lipid molecule from a membrane, its crossing through the hydrophilic cytoplasm and finally its adsorption into the target membrane [1]. However, such a mode of transport is precluded by the hydrophobicity of lipids therefore some proteins, termed Lipid Transfer Protein (LTP) are molecular devices able to convey lipids within the intracellular space [2][3]. The molecular details of LTP mode of action remain unclear, however they are propose to function in a stepwise manner, LTP mediate lipid extraction from a donor membrane, transfer it across a hydrophilic environment and deliver the lipid cargo to an acceptor membrane. Proteins from the START [(Steroidogenic Acute Regulatory protein) related lipid transfer] domain family are LTPs involved in the non-vesicular transport of lipids. START domain containing proteins (STARD) possess a START domain of about 210 amino acids which binds lipids [4-6]. Indeed, the threedimensional structure of the START domain defines a hydrophobic cavity that can accommodate one lipid molecule and thus serves as a "hydrophobic bridge" between the donor and the acceptor membrane [79]. The START domain may also sense lipids rather than transport them in some START proteins. Interestingly, START domain proteins have diverse lipid specificities and subcellular localizations which explain their specific role on lipid transport/sensing. In this report, we will review the current knowledge on their function.

\section{Diversity of the START domain protein family}

In humans, 15 different proteins possess one START domain. This domain is always unique and at the carboxy-terminus of the STARD proteins. Based on their sequence homology, these proteins have been categorized into 6 sub-families; interestingly, using this phylogenetic classification, proteins sharing a common lipid ligand and similar functions are grouped together (Figure 1).

\section{1: The organelle-bound cholesterol carriers group}

This group includes the two founding members of the START family, STARD1 (StAR: Steroidogenic Acute Regulatory Protein) and STARD3 (MLN64). Indeed, the identification of STARD1 a protein essential for steroidogenesis $[10,11]$ and of Metastatic Lymph Node 64 (MLN64/STARD3), a protein over-expressed in breast cancer [12], revealed the presence of a conserved domain in carboxyl-terminal position which was later named START domain. STARD1- and STARD3-START domains have similar biochemical properties: they both bind cholesterol at a 1:1 ratio and in a steroidogenesis assay, they are able in isolation to promote cholesterol transport from the outer to the inner mitochondrial membrane where it is available for the P450 side chain cleavage (P450scc) complex $[9,13][14]$. Despite these similarities, two main characteristics distinguish STARD1 and STARD3: first, their expression patterns since STARD1 is mainly expressed in gonads and adrenals while STARD3 is ubiquitous; second their subcellular localization as STARD1 is a mitochondrial protein while STARD3 is anchored to the limiting membrane of late endosomes. The differential expression pattern of STARD1 and STARD3 is explained by the transcription regulation of their respective encoding genes. STARD1 expression is tightly regulated by CAMP-dependent mechanisms in the adrenal and gonads in response to trophic hormones [luteinizing hormone(LH)/adrenocorticotropic hormone(ACTH)] [15][16]. STARD3 possesses features of an ubiquitous gene, its promoter is controlled by $\mathrm{Sp} / \mathrm{KLF}$ transcription factors [17]. The subcellular localization of both STARD1 and STARD3 is governed by their amino-terminal part: STARD1 has a targeting signal to the mitochondria $[18,19]$, while STARD3 has a membrane anchored domain, the MENTAL (MLN64 N-terminal) domain which anchors the protein to the limiting membrane of late endosomes [20][21] (Figure 2). Thus STARD1 and STARD3 provide a good 
illustration on how these two closely related proteins besides being both cholesterol transfer proteins, function in very distinct pathways.

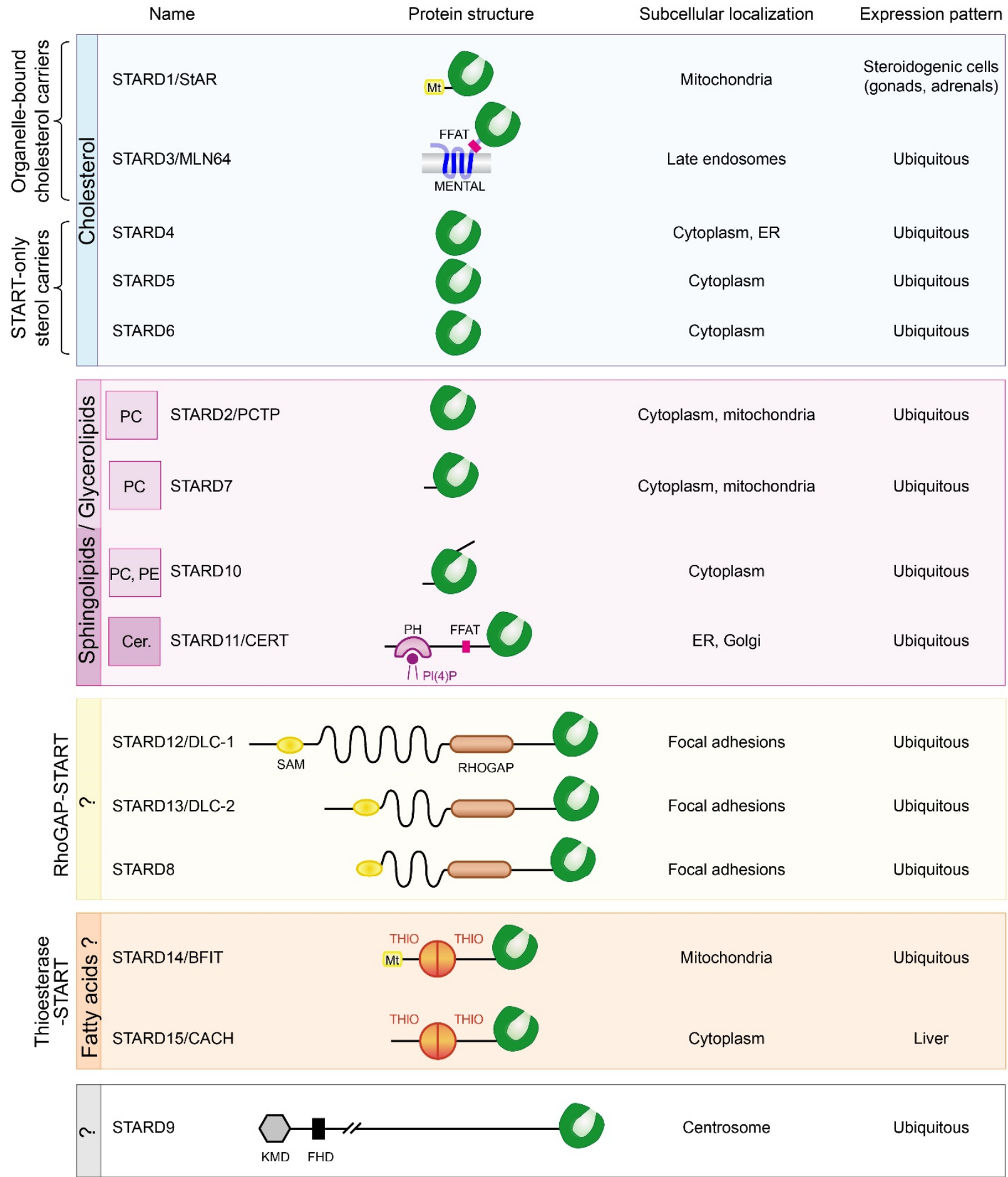

\section{Figure 1: START protein family structure}

The START protein family is divided into sub-families based on sequence homology within the START domain. Mt: mitochondria targeting signal; MENTAL: MLN64 N-terminal domain; PH: pleckstrin homology; FFAT: two phenylalanines in an acidic tract; THIO: hotdog-fold acyl-CoA thioesterase domain; SAM, sterile alpha motif; RHOGAP: GTPase activating protein; KMD: kinesin motor domain, FHD: FHA phosphoprotein binding domain

\subsubsection{STARD1 transports cholesterol to the mitochondria}

STARD1 is an essential protein in steroidogenesis: it is crucial to convey cholesterol to the mitochondria where it is metabolized into pregnenolone by the P450scc enzymatic complex [22]. Accordingly, STARD1 deficient mice die shortly after birth as a consequence of adrenal hormone absence; moreover, in these animals steroidogenic cells from gonads and adrenals which are unable to synthesize steroid hormones accumulate cytoplasmic lipid deposits [23]. Despite this well characterized function of STARD1 as a cholesterol supplier for the mitochondrial P450scc enzyme, its precise molecular mechanism of action is 
not ascertained. STARD1 is synthesized as a precursor which is processed by proteolytic cleavage when imported into the mitochondria. Strikingly, several reports have shown that STARD1 does not need to be imported into the mitochondria to be active. Indeed, it was shown that the association of the START domain of STARD1 with the outer mitochondrial membrane in absence of import and further processing is sufficient to promote cholesterol import and steroidogenesis $[24,25]$. The final import of the protein into the mitochondrial matrix is proposed to be the regulatory step shutting down STARD1 action. In mice, the re-expression of a STARD1 transgene in STARD1-deficient animals completely rescues viability and steroidogenesis. Interestingly, mice expressing a STARD1 truncated protein not targeted to the mitochondria have a higher viability and a partially restored steroidogenesis compared to knock-out mice, but still display lipid accumulation in the adrenal and gonads [26]. These data confirm that STARD1 is able to act without being targeted to the mitochondria, but also show that its correct subcellular localization is essential for a full activity in vivo. STARD1 was proposed to be part of a multi-protein complex at the interface between the inner and the outer mitochondrial membrane which would be the machinery responsible for cholesterol import towards P450scc [27][22].

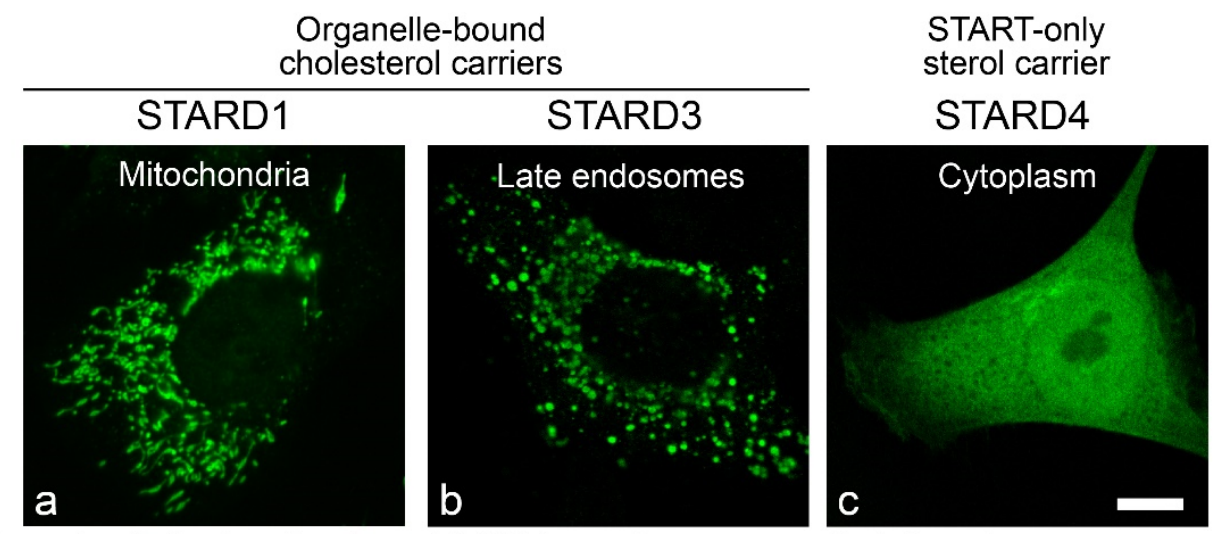

Figure 2: The subcellular localization of START proteins governs their function

Sub-cellular localization analysis of STARD1 (a), STARD3 (b) and STARD4 (c). Each protein was overexpressed in HeLa cells and its localization assessed by immunofluorescence. STARD1 and STARD3 are organelle-bound in the mitochondria and late endosomes respectively while STARD4 is cytoplasmic.

\subsubsection{STARD3 transports endosomal cholesterol}

Based on its wide expression pattern and conservation during evolution from worms to mammals, STARD3 is likely a protein involved in a basic cellular function [28]. The topology of STARD3 on the limiting membrane of endosomes orientates the START domain towards the cytoplasm. Interestingly, besides anchoring the protein in endosome membranes, the STARD3 MENTAL domain interacts with cholesterol in vivo; this suggests that the MENTAL domain is instrumental in the mechanism of cholesterol capture and transport mediated by STARD3 [29]. Moreover the MENTAL domain mediates homotypic as well as heterotypic interactions with a STARD3 related protein called STARD3NL (STARD3 N-terminal like alias MENTHO, MLN64 N-terminal Homolog), another MENTAL domain-bearing late endosomal protein $[21,29]$. In addition, this domain was shown to affect endosome dynamics since its expression induces an enlargement and a decreased mobility of endosome vesicles $[20,21,30,31]$. Up to now, the role of STARD3 on cholesterol transport remains unclear. STARD3 was suggested to transport cholesterol to the mitochondria [32][33]. However, STARD3 deficient mice are viable and do not display steroidogenesis defects but only slight sterol metabolic alterations [34].

These biochemical and cellular findings suggest that STARD3 is involved in the transport of cholesterol between late endosomes and most probably another organelle. Further studies should delineate the precise function of STARD3.

\section{2: The START-only sterol carriers group}

Among the START proteins family, three other members share affinity for cholesterol and hydroxycholesterol. These proteins named STARD4, STARD5 and STARD6 are only composed of a START domain [35]. The cholesterol binding properties of STARD4, D5 and D6 are similar to those of STARD1 and D3.

\subsubsection{STARD4 transports cholesterol to the $E R$}


STARD4 is a cytoplasmic protein which has been shown to associate with the endoplasmic reticulum $[4,36]$ (Figure 2). STARD4 seems to be involved in the transport of cholesterol to the ER which is a crucial event for cholesterol sensing in the cell. Indeed, cholesterol content in the ER regulates two major homeostatic systems: first, high cholesterol levels in the ER activate cholesteryl-ester formation catalyzed by the acylCOA:cholesterol acyl-transferase (ACAT) and second, low ER-cholesterol levels activate Sterol regulatory element-blinding protein-2 (SREBP-2) [37][38]. SREBP-2 is a transcription factor which is sequestered in an inactive form in the ER membrane under high cholesterol conditions. When cholesterol levels are lowered in the ER, SREBP is accompanied to the Golgi by SCAP (SREBP-cleavage activating protein) where it is cleaved to generate a transcriptionally-active protein which reaches the nucleus and activates the transcription of genes involved in cholesterol uptake and synthesis [37]. When STARD4 is overexpressed, it induces both cholesteryl-ester formation and ER-retention of SREBP2, events which both mark high ER cholesterol levels [39][40]. Conversely, siRNA mediated STARD4 down-regulation increases free cholesterol level which is probably a consequence of a lower supply of cholesterol to the ER for esterification by the ACAT. Intriguingly, STARD4 role on intracellular cholesterol transport can be substituted by methyl- $\beta$-cyclodextrin, a chemical compound with affinity for cholesterol. Indeed, microinjection of methyl- $\beta$-cyclodextrin in cells lacking STARD4 is able to restore a normal cholesterol transport towards the ER [39]. Therefore STARD4 seems to be a non-selective cholesterol transporter which equilibrates cholesterol content between cellular membranes, a crucial function for cholesterol sensing in the ER [41]. In line with this, STARD4 is directly regulated by SREBP2 $[35,36,42]$. Surprisingly, STARD4 deficient mice only display minor alterations in lipid metabolism which suggests a functional redundancy with other intracellular cholesterol transporters [43].

\subsubsection{STARD5 is likely a bile acid transporter}

STARD5 has been reported to bind both cholesterol and hydroxycholesterol [40][44][14]. However, it was recently suggested that STARD5 binds primary bile acids (cholic and chenodeoxycholic acid) rather than cholesterol [45]. This suggests that STARD5 might be involved in bile acid transport or sensing. However, further works are needed to fully understand the function of this protein.

\subsubsection{STARD6, a male germ cell cholesterol transporter}

STARD6 is almost exclusively expressed in male germ cells $[35,46]$. Interestingly, STARD6 is more efficient than STARD1 to transport cholesterol to the mitochondria in a pregnenolone synthesis assay [14]. However, up to now, the function of this protein remains unknown. It might be involved in the transfer of cholesterol to the mitochondria or other membranes of male germ cells.

\section{3: The Phospholipids/Ceramide carriers group}

This subgroup is more heterogenous as STARD2/PCTP, STARD7, STARD10 and STARD11/CERT/GPBP have different structural organization and ligand specificity. STARD2, STARD7 and STARD10 are START-only proteins while STARD11 has two additional functional domains interacting with membranes, a PH domain (Pleckstrin homology) and a FFAT motif (two phenylalanine in an acidic tract) as well as a coiled-coil and two serine-rich motifs. STARD2, STARD7 and STARD10 bind phosphatidylcholine (PC) and STARD10 also binds phosphatidylethanolamine (PE) [47-49]. STARD11 binds ceramides [50]. These four proteins are ubiquitously expressed suggesting that they perform a general function in lipid transport.

\subsubsection{STARD2, STARD7 and STARD10 mediate PC transport}

STARD2/PC-TP (phosphatidylcholine transfer protein) promotes the rapid exchange of phosphatidycholine (PC) probably from its site of synthesis to the plasma membrane and / or the mitochondria [51]. Accordingly, STARD2 is mainly found in the cytoplasm as well as associated to the mitochondria, a localization which seems to be controlled by the phosphorylation of STARD2 at serine 110 $[52,53]$. Though specific for PC, STARD2 exhibits preference towards some PC species with sn-1 palmitoyl $(16: 0)$ and sn-2 unsaturated acyl chains (Kang et al., 2010). This preference might regulate STARD2 activity according to membrane composition [51].

The STARD7 gene encodes two protein variants which are generated by alternative translation initiation: the shorter isoform is cytoplasmic while the longer has an extra amino-terminus functioning as a mitochondrial targeting sequence [47]. This finding therefore suggests that STARD7 is involved in PC transport to the mitochondria [54]. 
Interestingly, STARD10 is phosphorylated on serine 284 by casein kinase II. This residue is positioned within an acidic sequence at the carboxy-terminus of the protein. Serine 284 phosphorylation inhibits STARD10 lipid transfer activity. Conversely, replacement of this serine by a non-phosphorylable residue increases STARD10 activity. Serine 284 phosphorylation regulates STARD10 by preventing its interaction with membranes, most probably through electrostatic repulsion [55]. This type of post-translational modification is therefore an efficient mean to regulate the function of the START domain.

\subsubsection{STARD11/CERT mediates ER to Golgi ceramide transport}

STARD11 is one of the best characterized START protein. It mediates non-vesicular transport of ceramide from its site of synthesis in the ER to the Golgi apparatus where it is converted into sphingomyelin [50]. Additionally, CERT-transported ceramide might serve as substrate to glucosylceramide synthase which synthetizes glucosylceramides (GlcSer) in the Golgi [56]. STARD11 can efficiently transfer several species of ceramide with long chain fatty acid (C14-C20) [57]. While in vitro, the transfer of ceramide from donor to acceptor membranes only requires the START domain, in vivo, STARD11 function involves the cooperation of several protein modules, namely the PH domain and the FFAT motif [58]. The unique role of STARD11 on ceramide transport was confirmed in deficient mice. STARD11 -/- mice die during embryogenesis around E11.5 as a result of cardiovascular insufficiency. In STARD11 deficient embryos, the ER exhibits several morphological alterations which are accompanied by ceramide accumulation and a global decrease in sphingomyelin content [59]. Strikingly, cells also display mitochondria alterations which may result from a ceramide mislocalization to this organelle induced by STARD11 absence.

\section{4: The RhoGAP-START group}

This group comprises three proteins: STARD8 (DLC-3), STARD12 (DLC-1) and STARD13 (DLC-2) which all have a SAM (Sterile Alpha motif), a Rho-GAP (Rho-GTP activating protein) and a START domain [60][61][62]. The function of the SAM domain in these proteins is not yet fully understood. However, it was reported that the SAM domain of STARD12 interacts with eukaryotic elongation factor 1A1 (EF1A1), a protein involved in cell growth/death and cytoskeletal network control [63]. This interaction allows the efficient localization of EF1A1 to the membrane periphery and ruffles and restrains migration in a RhoGAP dependent manner.

Up to now, the main known biological activity of STARD8/D12 and D13 is mediated by their Rho-GAP domain. This domain regulates Rho GTPases activity by favoring the hydrolysis of GTP thereby allowing the switch from the active to the inactive conformation of the protein. STARD12 exerts a Rho-GAP activity in vitro on RhoA, RhoB, RhoC and to a lesser extent on Cdc42; STARD8 and STARD13 are both active on RhoA and Cdc42 $[64,65][66][67,68]$. In accordance with this activity on Rho GTPases, STARD8 or D12 or D13 overexpression was shown to affect the actin cytoskeleton with a disruption of actin stress fibers and a resulting change in cell morphology, an effect that was dependent on an active Rho-GAP domain [65][69][64].

Between the Rho-GAP and the START domain is positioned an unstructured region which is responsible for the targeting of STARD8/D12 and D13 to focal adhesions [65][70][71]. Interestingly, this region was shown to interact with the Src homology $2(\mathrm{SH} 2)$ domain of cten (C-terminal tensin like) and the PTB domain of tensin 1 and 2, which are focal adhesion resident proteins, thereby explaining the recruitment of STARD8/D12 and D13 in these specialized areas of the plasma membrane [72][73] [61].

Thus, the three proteins STARD8, D12 and D13 are highly similar in terms of structure, cellular localization and role on the actin cytoskeleton which suggests that they have redundant functions. In accordance with this, STARD13-deficient mice are viable and develop normally [74]. However, pancreas-specific ablation of STARD13 was recently shown to affect pancreatic development. In these animals, the pancreas displays a reduced size and epithelial morphogenesis defects linked to the actin cytoskeleton [75]. In contrast, STARD12 ablation results in embryonic lethality before E10.5 which suggests that this protein has unique functions which cannot be compensated by STARD8 or STARD13 $[74,76]$.

The position of STARD8, D12 and D13 at specific subcellular localizations, their ability to activate small GTP-binding proteins that play a central role in diverse biological processes such as intracellular traffic, adhesion, polarity, motility and cell division raise the possibility that they act locally to initiate regulatory signaling cascades in a lipid binding dependent manner. In other words, proteins from this subfamily might represent signaling relay for their lipid ligands whose identification is unfortunately missing. In line with this hypothesis, STARD13 was shown to mediate ceramide signaling in Chinese hamster ovary cells. Indeed, STARD13 is required to induce mitochondrial phosphatidylglycerolphosphate (PGP) synthase 
activition in response to ceramides, a function that was linked to RhoA activity [77]. STARD13 seems therefore to connect lipid biosynthesis and RhoA activity.

\section{5: The thioesterase group}

This group consists of two proteins, STARD14 and STARD15, and is part of the acyl-CoA thioesterase (ACOT) family known to hydrolyze acyl-CoA molecules. The presence of a START domain distinguishes STARD14 and 15 from the other ACOT proteins. Indeed, STARD14 (ACOT11/BFIT/Them1) and STARD15 (ACOT12/CACH) associate two hot dog-like thioesterase domains (THIO) with a START domain [78]. The ligand of STARD14- and STARD15-START domains is unknown though crystallographic studies indicate that it might be a fatty acid [79].

\subsubsection{STARD14 hydrolyses long-chain fatty acyl-CoA}

STARD14 was shown to be preferentially active towards long-chain fatty acyl-CoAs, its active form being a dimer. While THIO domains of STARD14 are active in isolation, the START domain is necessary for optimal enzyme activity [80]. Alterative splicing generates two STARD14 isoforms with distinct START domain carboxy-terminal ends [81]. However, the exact contribution of these variants is unclear. Interestingly, the amino-terminal end of STARD14 was shown to be an operative mitochondria targeting signal [82]. However, the enzymatic activity of STARD14 was mainly found in the cytosol and microsomes in mouse tissues [80].

\subsubsection{STARD15 hydrolyses acetyl-COA}

STARD15 differs from STARD14 in substrate specificity, it acts preferentially on acetyl-CoA [83]. STARD15 is mainly expressed in the liver and is cytoplasmic [84].

Despite their common structural traits, STARD14 and STARD15 have different expression patterns, subcellular localizations and substrate specificities. The presence of a START domain in these enzymes suggests that it might be involved in supplying substrates to the catalytically active THIO domain.

\section{6: STARD9, a unique member of the family}

Among the START protein family, STARD9 has unique features: it is a large protein of more than $500 \mathrm{kDa}$ with a modular organization consisting of an $\mathrm{N}$-terminal kinesin motor domain, an FHA phosphoprotein binding domain and a C-terminal START domain [85]. Based on homology, STARD9 belongs to the kinesin3 family and is therefore also named Kif16a [86]. STARD9 was shown to associate with centrosomes and to be crucial for mitosis. Indeed, STARD9-depleted cells display several mitosis defects which ultimately lead to apoptosis. Interestingly, STARD9 inactivation was shown to synergize with taxol to trigger apoptosis making this protein a potential therapeutic target in cancer therapy [85]. Most intriguingly, the role of the START domain in STARD9 remains unknown though its presence suggests a link between lipids and centrosome function.

\section{Molecular mechanism of START proteins action}

\subsection{The 3D structure of the START domain defines a lipid binding cavity}

The three-dimensional structures of 8 out of 15 START proteins have been described (STARD1, D2, D3, D4, D5, D11, D13 and D14) [7-9,87][79]. They all display similar structural features with a helix-grip fold consisting in a central anti-parallel $\beta$-sheet with $9 \beta$-strands gripped by two $\alpha$ helices ( $\alpha 1$ and $\alpha 4$ ) (Figure 3). Two $\Omega$ loops ( $\Omega 1$ and $\Omega 2$ ) are inserted between strands $\beta 5 / \beta 6$ and strands $\beta 7 / \beta 8$, respectively. Interestingly, the START domain defines an amphiphilic inner cavity which was shown to be wide enough to accommodate one lipid molecule [9]. Moreover, STARD2 and STARD11 have been crystallized with one ligand molecule (PC and ceramide, respectively) (Figure 3) $[7,87]$. In these two structures, the lipid molecule is buried within the START domain cavity, the hydrophilic head being in the innermost part of the cavity where it interacts with specific residues and the acyl chains being surrounded by the hydrophobic walls. The narrow opening of the cavity implies that the START domain needs structural rearrangements to take up the lipid molecule. Several models have been proposed to explain this structural change: the START domain was proposed to partially unfold in a "molten globule" conformation. For STARD1, this transition occurs at low $\mathrm{pH}$, a condition that could be found at the outer mitochondria and therefore allow STARD1 to transport cholesterol at this specific place [88]. Alternatively, structural rearrangements involving movement of the $\alpha 4$ helix and/or the $\Omega 1$ loop were proposed 
[89][90]. Interestingly, molecular dynamics simulations favor the sole involvement of the $\Omega 1$ loop which appears to be highly dynamic [87][91]. Moreover, in other clades, START domains are not systematically located at the carboxy-terminal end of proteins but can be followed by other domains such as a DUF1336 domain in plants (rice, thale cress...) or a Fbox and a WD40 domain in some protists (Dictyostelium discoideum), which argues against a role for the $\alpha 4$ helix as a lid [92].
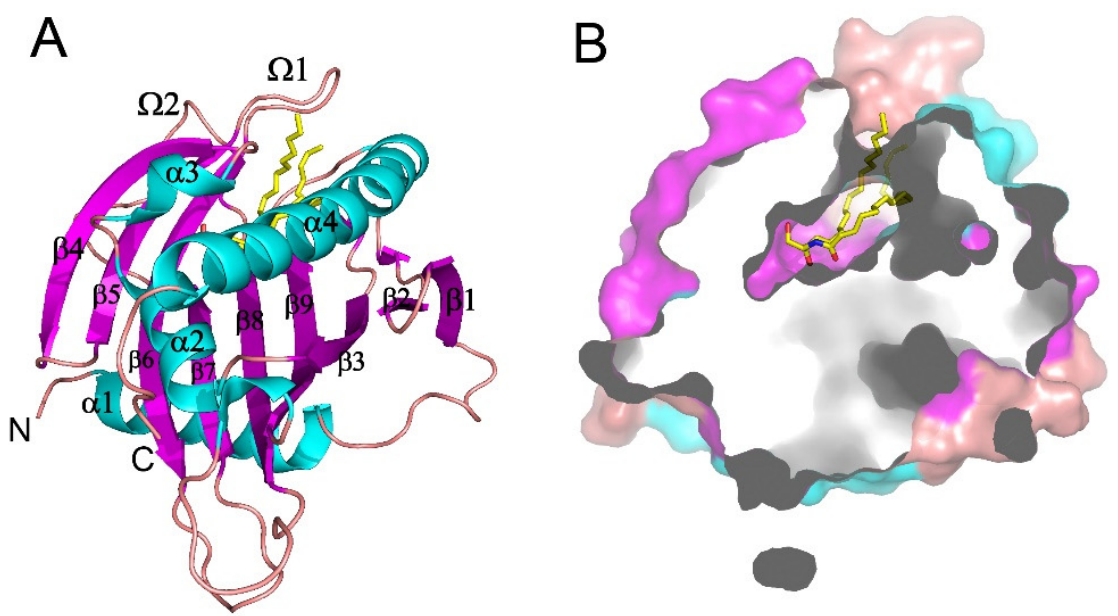

Figure 3: The START domain structure forms a cavity encompassing one lipid molecule

Structure of the START domain of STARD11 with a C18 ceramide molecule (PDB ID:2e3q) [87]. $\alpha$ helices (magenta: 1-4), $\beta$ sheets (cyan: $1-9$ ) and $\Omega$ loops (orange: 1,2) are numbered from the amino- to the carboxy-terminus. $C, N$ and $O$ atoms within the ceramide molecule are in yellow, blue and red, respectively. Ribbon drawing (A) and cut-away view of the molecular surface (B) are shown. These figures were prepared with PyMOL (The PyMOL molecular graphics system. http://www.pymol.org).

\subsection{The START domain is attracted by membranes}

The ability of START proteins to transport lipids suggests that they are able to sense membranes in order to take up and deliver their ligand. Accordingly, the presence of membrane interacting surfaces on the START domain has been proposed. For instance, the partially amphiphilic $\alpha 4$ helix of STARD2 was shown to favor membrane interaction [93]. Similarly, STARD11 possesses exposed hydrophobic residues in the $\Omega 1$ loop which are crucial for its ceramide transport activity [87]. As a last example, STARD4 exhibits a patch of basic residues near the $\Omega 1$ loop which is required for an efficient lipid transport; accordingly, electrostatic interaction between STARD4 and anionic lipids were shown to enhance STARD4 activity $[8,39]$. These models support the notion that within the START domain, structural elements must guide the domain with respect to the biological membrane and ensure a positioning favorable for the exchange of the lipid ligand. In addition, as suggested by studies on STARD10 phosphorylation (see above), the interaction with membranes is probably a way to regulate the function of the START domain.

\subsection{START proteins likely acts preferentially in inter-organelle membrane contact sites} (MCS)

The lipid transport activity mediated by START proteins is likely favored by the proximity between the donor and the acceptor membrane. Interestingly, membrane contact sites where the membranes of two organelles are apposed have been observed in cells. These MCS involve predominantly the ER which contacts several other organelles [94,95]. The involvement of MCS in START-mediated lipid transport is supported by the characterization of STARD11 protein [58]. As stated earlier, STARD11 has two protein modules, a PH domain and a FFAT motif, that define its interaction with two organelles, the Golgi and the ER, respectively. Indeed, the PH domain of STARD11 binds to PI4P, a phosphoinositide highly enriched in the Golgi membrane [96]. The FFAT motif is a small peptide which binds to ER membrane proteins called vesicle-associated membrane-associated protein (VAP-A and VAP-B) [97]. A model of STARD11 action in ceramide transport has therefore been proposed [58].The binding of STARD11 to the ER through its FFAT motif allows the START domain to take up one ceramide molecule from the ER membrane. The PH domain of STARD11 then targets the protein to the Golgi where the ceramide molecule is released. To achieve its function, STARD11 might shuttle between the two organelles. Alternatively and more probably, the protein might bind simultaneously to the two membranes and therefore act within MCS [98]. In this scenario, the START domain efficiently transfers ceramide molecules by a 'neck-swinging' movement (Figure 4). The characterization of STARD11 regulation by phosphorylation reinforced this model. Indeed, 
STARD11 phosphorylation in a serine-rich motif was shown to inhibit its function, the level of phosphorylation resulting from a balance between phosphorylation by Protein Kinase $D$ (PKD) and casein kinase I (CKI $\gamma 2$ ) and dephosphorylation by protein phosphatase $2 \mathrm{C} \varepsilon$ (PP2C $\varepsilon$ ). Accordingly, a nonphosphorylable mutant of STARD11 (S132A) was shown to be more active than wild-type protein. Interestingly, while wild-type STARD11 is localized in the cytoplasm and associated with the Golgi, the S132A mutant was predominantly associated with the Golgi. One interesting possibility would be that active STARD11 is localized in ER-Golgi MCS.

The characterization of STARD11 therefore suggests that some START proteins have the ability to generate inter-organelle MCS or to be recruited to these specialized areas of the cell. This original positioning should indeed facilitate START proteins lipid transfer activity. However, further work is required to precisely delineate START proteins role in organelles tethering and its consequence on lipid transport.

Some lipid transfer proteins have the ability to counterexchange two lipid species between membranes [99]. For instance, Osh4p, a yeast Oxysterol-binding homology / Oxysterol-binding protein-related (Osh/ORP) protein transports sterol and PI4P between membranes along opposite routes [99]. This original lipid transfer activity, found in other LTP families such as the Sec14p or the PITP family, could therefore be present in the START family [3]. In line with this, STARD11 binds weakly diacylglycerol, a byproduct of sphingomyelin synthesis; it was therefore proposed that STARD11 transports ceramide from the ER to the Golgi where it is metabolized into sphingomyelin, and exchanged for diacylglycerol [100].
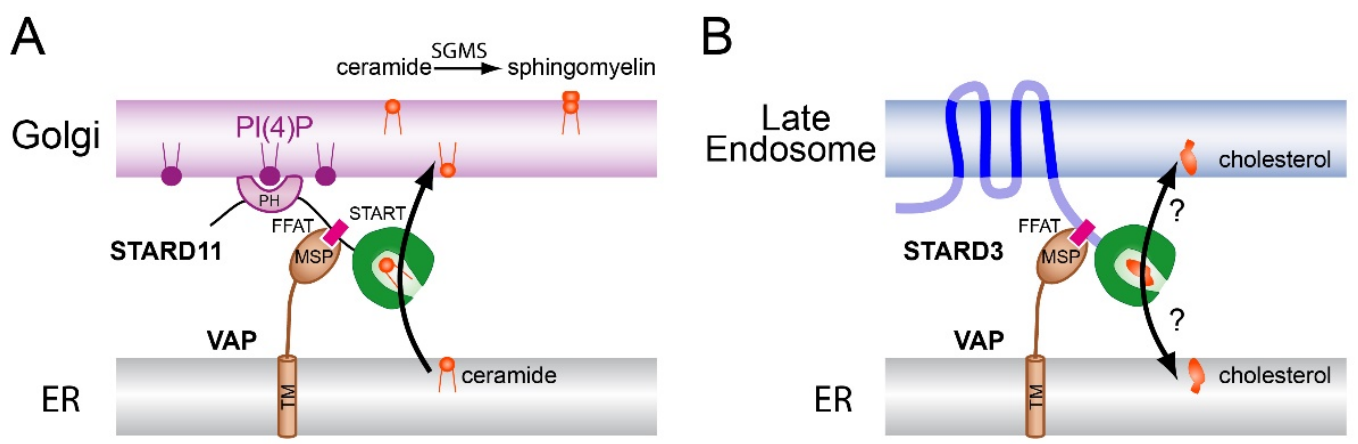

Figure 4: STARD11 mediates ceramide transfer from ER to Golgi through membrane contact sites

MSP: major sperm protein domain; TM: transmembrane domain; PI4P: Phosphatidylinositol 4-phosphate; SGMS: sphingomyelin synthase.

\section{START proteins in lipid metabolism}

\subsection{START proteins deficiency may affect lipid content in some organs}

The role of START proteins in intracellular lipid transport suggests that they have a function in lipid metabolism. Several START protein deficient mouse models have been generated and their lipid metabolism analyzed. Surprisingly, most of these deficient mice models only display minor metabolic defects with a modest modification of lipid content in some tissues. For instance, STARD3 deficient mice only show a slight increase in sterol ester storage when fed a high fat diet [34]. In the same line, female STARD4 knockout mice merely display moderate LDL and cholesterol decrease when fed a $0.5 \%$ cholesterol diet [43], and STARD13 -/- mice are lighter with less fat tissue than WT mice [74]. These data suggest the existence of functional redundancies in lipid transport mediated by most START proteins, which is likely operated by other START proteins from the same group or by other lipid transfer proteins such as Osh/ORP proteins [41].

For other START proteins, the phenotype observed was quite surprising. STARD10 is a phosphatidylcholine transfer protein highly expressed in the liver. Surprisingly, STARD10 deficient mice do not display defects in PC secretion into the bile nor in PC content in the liver [101]. Rather, they secrete higher amounts of bile acids, primarily taurine-conjugated. In addition, the level of secondary bile acids in the liver of STARD10-deficient mice is lower. Since secondary bile acids result from primary bile acids modifications in the intestinal lumen and are reabsorbed by the intestine and delivered back to the liver, this phenotype suggests that these mice have an impairment of the enterohepatic cycling. In fact, the apical sodiumdependent bile acid transporter (or solute carrier family 10, member 2 SLC10A2), which is responsible for reabsorbing the majority of bile acids from the intestinal lumen exhibits a highly decreased expression level in the intestine of these mice. Accordingly, the fecal excretion of bile acids is increased in STARD10deficient mice [101]. Interestingly, some Peroxisome proliferator-activated receptor alpha (PPAR $\alpha$ ) 
regulated genes responsible for bile acid metabolism regulation are affected in the liver of Stard10 deficient mice, which suggests that STARD10 loss modulates PPAR $\alpha$ activity. Similarly to STARD10, STARD2 transfers PC in vitro and unexpectedly STARD2 knock-out animals do not display defects in PC secretion into the bile or into surfactant, two biological fluids highly enriched in this lipid [102][51]. However, STARD2 was shown to be involved in adaptive thermogenesis, as discussed below.

Other START proteins (e.g. STARD11) are unique; deficient mice die early during development and fail to provide physiological insight into the function of these proteins regarding lipid metabolism.

\subsection{STARD2 and STARD14 modulate energy consumption and thermogenesis}

The characterization of STARD2 interaction partners uncovered a potential functional link with STARD14 (aka ACOT11). Indeed, STARD2 was shown to interact with the acyl-CoA thioesterase ACOT13 (aka Them2) [53]. Therefore, STARD2/ACOT13 interaction brings together two protein domains, namely START and THIO domains, in STARD2 and ACOT13 respectively. Strikingly, these two domains are associated within a single protein in STARD14. This link is corroborated by the similarity between STARD2 and STARD14 knockout mice phenotypes.

STARD2 was reported to regulate adaptive thermogenesis in brown adipose tissue [103]. Indeed, STARD2 expression varies inversely to the ambient temperature. Moreover, STARD2 deficient mice show an increased body temperature at room temperature and are able to efficiently maintain their temperature when placed in a cold environment [103]. Accordingly, brown fat, the main tissue involved in thermogenesis, displayed cells with enlarged and elongated mitochondria. This morphological modification was accompanied with an increase in thermogenic genes expression and increased fatty acid consumption [103][104]. Hence, STARD2 -/- mice have an adaptive increase in body fat.

STARD14 is another START protein involved in the regulation of thermogenesis. STARD14 was initially named BFIT (Brown Fat Inducible Thioesterase) as this gene is induced in the brown adipose tissue of coldchallenged animals [81]. STARD14 deficient mice are viable and grow normally [105]. Despite nearly twofold increased food consumption, they are resistant to diet-induced obesity. This is explained by an increased energy expenditure which is characterized by increased oxygen consumption and heat production. In order to be used for energy production, fatty acids are activated by acyl-CoA synthetases to generate fatty acyl-CoAs which can be catabolized by the $\beta$-oxidation pathway in the mitochondria. Alternatively, fatty acyl-CoAs can be hydrolyzed into fatty acid and CoA by ACOTs which are enzymes proposed to regulate fatty acyl-CoAs levels. Accordingly, STARD14 (aka ACOT11) deficient mice display higher long-chain fatty acyl-CoAs levels, increased fatty acid oxidation and up-regulation of genes that promote energy expenditure in brown adipose tissue. STARD14 -/- mice are also protected against dietinduced inflammation in white adipose tissue, hepatic steatosis and show improved glucose homeostasis. These data suggest that STARD14 operates to decrease energy consumption which in the context of nutritional excess may ultimately lead to insulin resistance. Therefore, STARD14 may be a useful target in metabolic syndrome.

\section{Involvement of START proteins in diseases}

\subsection{STARD1 is mutated in a genetic disorder, congenital lipoid adrenal hyperplasia}

Several diseases are associated with START proteins. The first disease associated to this protein family was congenital lipoid adrenal hyperplasia, a recessive genetic disorder in which many mutations of STARD1 have been identified [11]. This disease is characterized by a complete lack of steroid hormones synthesis which is accompanied by a pathological accumulation of cholesterol in lipid droplets within the gonads and adrenal glands [106]. This phenotype reflects the inability of mutant STARD1 protein to transport cholesterol across the mitochondrial membranes to allow its conversion into pregnenolone, the precursor of steroid hormones [22].

\subsection{START proteins in cancer}

START proteins are commonly linked to a second condition which is cancer. Indeed, the expression of several START domain proteins is altered in cancers. For instance, breast cancers overexpressing the erbB2/HER2 gene, a member of the EGF receptor family, also overexpress STARD3 $[12,107]$ and STARD10 $[48,108]$. STARD3 and ErbB2 genes are co-located on chromosome 17 q12-q21, a region frequently amplified in breast cancers. The proximity of the two genes and their identical promoter regulatory elements explain their coexpression and suggest that they cooperate in malignant transformation [17]. 
Indeed, STARD3 downregulation was shown to impair cell growth in ErbB2-amplified cell lines [109][110]. STARD10 overexpression in breast cancer is quite broad and is not limited to ErbB2 positive cases. However, a link has been found between STARD10 and EGF receptor (EGFR/ErbB1). Indeed, STARD10 cooperates with ErbB1 in the process of malignant transformation, suggesting a role for this protein in the cancerous phenotype [108]. Intriguingly, a retrospective clinical study associated a loss of STARD10 expression with a poor clinical outcome both in ErbB2 positive and negative tumors [111]. In line with this, STARD10 was recently identified as a target of miR-661 during SNAI1-induced epithelial to mesenchymal transition thus suggesting that STARD10 loss of expression could be a feature of aggressive mesenchymal tumors [112].

Some START domain proteins encoding genes are inactivated in cancer. STARD12 gene originally named Deleted in Liver Cancer 1 (DLC-1) is a tumor suppressor located on chromosome 8 p21-22, a region exhibiting frequent loss of heterozygosity in cancer [113][114][60]. This gene is lost in some liver and breast primary tumors $[68,113,115]$ and is under-expressed in tumors cell lines derived from liver, breast, colon and prostate $[116,117]$. Interestingly, STARD12 is a target of Hepatitis C virus (HCV), a major cause of hepatocellular carcinoma. Indeed, HCV infection was shown to induce expression of the microRNA miR141 which targets STARD12 for silencing; in turn, STARD12 silencing enhances cell proliferation and HCV replication, which is probably a mechanism of HCV-associated carcinogenesis [118]. In line with its tumor suppressor function, STARD12 re-expression in cancer cell lines from different origin inhibits their growth in vitro and in vivo $[117,119,120][121,122]$. The other two members of the Rho-GAP-START subfamily STARD13 and STARD8 are also potential tumor suppressor genes. Indeed, STARD13 is located in 13q12.3, a chromosomal region with frequent allelic loss in hepatocellular carcinoma and other cancers [64][123]. STARD8 also presents a loss of expression in certain cancers and seems to have a tumor suppressor function [124]. The high conservation of these genes suggests that they are involved in similar functions in cancer. Rho GTPase activity was shown to contribute to cancer initiation/progression. Since STARD8, STARD12 and STARD13 are Rho-GAP proteins which inactivate Rho GTPase, their loss by removing a Rho GTPase inactivation mechanism favors tumorigenesis. Thus their function in cancer likely occurs through their Rho-GAP activity rather than their START domain.

5.3. STARD11 is involved in an autoimmune syndrome, pathogen infection and cancer The ceramide transport protein STARD11 was initially called Goodpasture binding protein (GPBP) or Collagen alpha3 (IV) chain binding protein (COL4A3BP). Indeed, STARD11 was proposed to be involved in Goodpasture syndrome, a disease characterized by the production of autoantibodies against the NC1 domain of collagen IV $\alpha 3$ chain, a component of basement membranes [125]. However, the link between STARD11 and the pathology is not fully understood. Though devoid of a recognizable kinase motif, STARD11 was proposed to bind and phosphorylate the antigen in this disease. In mice, STARD11 overexpression results in glomerular basement membrane disruption and immunoglobulin type $A$ deposition which are clinical signs of lupus nephritis [126].

STARD11 was involved in host-pathogen interactions in cells infected by the intracellular bacteria Chlamydia trachomatis. Indeed, this pathogen resides in a membrane-bound vacuole which recruits STARD11 thanks to the bacterial protein InCD. STARD11 in turn interacts with VAP protein thereby promoting ER-inclusion membrane contact sites formation. This hijacking of the host protein STARD11 might be a ceramide supply route for the bacteria $[127,128]$.

Finally, STARD11 is involved in cancer. Indeed, STARD11 has been implicated in the mechanisms of sensitivity to drugs used in chemotherapy, and in particular paclitaxel, a molecule of the taxane family which inhibits microtubule [129]. STARD11 by changing the ceramide content in cancer cells may modulate their response to apoptotic signals induced by the drug. In cancer cells, STARD11 depletion was shown to induce cell death through an autophagy-dependent pathway [130]. Thus, STARD11 expression may be a useful prognosis marker and potentially an additional therapeutic target in tumors resistant to chemotherapy. Interestingly, several inhibitors of STARD11 have been identified, such as the chemical compound HPA-12 as well as some limonoids which are natural compounds employed in traditional medicine [131][132]. Given the common alteration of START proteins in a variety of pathologies including cancer, START proteins may indeed represent novel target for therapies. 


\section{Conclusion}

The basic study of START proteins provides important advances in our knowledge of the mechanisms underlying intracellular lipid traffic. The characterization of several START domains by structural, biophysical and biochemical studies allows to propose different mechanistic models of lipid transfer. The generation of several START protein deficient mouse models underlines unique roles for few members and redundant roles for most START proteins. Besides, the characterization of additional structural and catalytic domains present in complex START proteins indicates that they likely belong to molecular machineries devoted to the traffic, sensing and/or signaling of lipids within the cell. Future work will further clarify the molecular identities of these machineries and how they are interconnected to other cellular processes.

\section{Acknowledgements:}

We wish to thank Adrien Rousseau and the members of the Molecular and Cellular Biology of Breast Cancer team (IGBMC) for helpful discussions. We also acknowledge funds from the Institut National de Sante et de Recherche Médicale (INSERM), the Centre National de la Recherche Scientifique (CNRS), the Université de Strasbourg (UDS), and the Ligue Contre le Cancer (CCIR-GE).

\section{Bibliography:}

[1] S. Lev, Non-vesicular lipid transport by lipid-transfer proteins and beyond, Nat Rev Mol Cell Biol. 11 (2010) 739-50.

[2] J.C. Holthuis, T.P. Levine, Lipid traffic: floppy drives and a superhighway, Nat Rev Mol Cell Biol. 6 (2005) 209-20.

[3] G. D'Angelo, M. Vicinanza, M.A. De Matteis, Lipid-transfer proteins in biosynthetic pathways, Curr Opin Cell Biol. 20 (2008) 360-70.

[4] F. Alpy, C. Tomasetto, Give lipids a START: the StAR-related lipid transfer (START) domain in mammals, J Cell Sci. 118 (2005) 2791-801.

[5] C.P. Ponting, L. Aravind, START: a lipid-binding domain in StAR, HD-ZIP and signalling proteins, Trends Biochem Sci. 24 (1999) 130-2.

[6] R.E. Soccio, J.L. Breslow, StAR-related lipid transfer (START) proteins: mediators of intracellular lipid metabolism, J Biol Chem. 278 (2003) 22183-6.

[7] S.L. Roderick, W.W. Chan, D.S. Agate, L.R. Olsen, M.W. Vetting, K.R. Rajashankar, et al., Structure of human phosphatidylcholine transfer protein in complex with its ligand, Nat Struct Biol. 9 (2002) 507-11.

[8] M.J. Romanowski, R.E. Soccio, J.L. Breslow, S.K. Burley, Crystal structure of the Mus musculus cholesterol-regulated START protein 4 (StarD4) containing a StAR-related lipid transfer domain, Proc Natl Acad Sci U S A. 99 (2002) 6949-54.

[9] Y. Tsujishita, J.H. Hurley, Structure and lipid transport mechanism of a StAR-related domain, Nature Structural \& Molecular Biology. 7 (2000) 408-414.

[10] B.J. Clark, J. Wells, S.R. King, D.M. Stocco, The purification, cloning, and expression of a novel luteinizing hormone-induced mitochondrial protein in MA-10 mouse Leydig tumor cells. Characterization of the steroidogenic acute regulatory protein (StAR), J Biol Chem. 269 (1994) 28314-22.

[11] D. Lin, T. Sugawara, J.F. Strauss, B.J. Clark, D.M. Stocco, P. Saenger, et al., Role of steroidogenic acute regulatory protein in adrenal and gonadal steroidogenesis, Science. 267 (1995) 1828-31.

[12] C. Tomasetto, C. Regnier, C. Moog-Lutz, M.G. Mattei, M.P. Chenard, R. Lidereau, et al., Identification of four novel human genes amplified and overexpressed in breast carcinoma and localized to the q11-q21.3 region of chromosome 17, Genomics. 28 (1995) 367-76.

[13] H. Watari, F. Arakane, C. Moog-Lutz, C.B. Kallen, C. Tomasetto, G.L. Gerton, et al., MLN64 contains a domain with homology to the steroidogenic acute regulatory protein (StAR) that stimulates steroidogenesis, Proc Natl Acad Sci U S A. 94 (1997) 8462-7.

[14] H.S. Bose, R.M. Whittal, Y. Ran, M. Bose, B.Y. Baker, W.L. Miller, StARlike activity and molten globule behavior of StARD6, a male germ-line protein, Biochemistry. 47 (2008) 2277-88.

[15] D.M. Stocco, X. Wang, Y. Jo, P.R. Manna, Multiple Signaling Pathways Regulating Steroidogenesis and Steroidogenic Acute Regulatory Protein Expression: More Complicated than We Thought, Molecular Endocrinology. 19 (2005) 2647-2659.
[16] P.R. Manna, M.T. Dyson, D.M. Stocco, Regulation of the steroidogenic acute regulatory protein gene expression: present and future perspectives, Mol. Hum. Reprod. 15 (2009) 321-333.

[17] F. Alpy, A. Boulay, C. Moog-Lutz, K.L. Andarawewa, S. Degot, I. Stoll, et al., Metastatic lymph node 64 (MLN64), a gene overexpressed in breast cancers, is regulated by Sp/KLF transcription factors, Oncogene. 22 (2003) 3770-80.

[18] L.F. Epstein, N.R. Orme-Johnson, Regulation of steroid hormone biosynthesis. Identification of precursors of a phosphoprotein targeted to the mitochondrion in stimulated rat adrenal cortex cells., J. Biol. Chem. 266 (1991) 19739-19745.

[19] D.M. Stocco, T.C. Sodeman, The 30-kDa mitochondrial proteins induced by hormone stimulation in MA-10 mouse Leydig tumor cells are processed from larger precursors., J. Biol. Chem. 266 (1991) 1973119738.

[20] F. Alpy, M.E. Stoeckel, A. Dierich, J.M. Escola, C. Wendling, M.P. Chenard, et al., The steroidogenic acute regulatory protein homolog MLN64, a late endosomal cholesterol-binding protein, J Biol Chem. 276 (2001) 4261-9.

[21] F. Alpy, C. Wendling, M.C. Rio, C. Tomasetto, MENTHO, a MLN64 homologue devoid of the START domain, J Biol Chem. 277 (2002) 50780-7.

[22] B.J. Clark, The mammalian START domain protein family in lipid transport in health and disease, J Endocrinol. 212 (2012) 257-275.

[23] K.M. Caron, S.C. Soo, W.C. Wetsel, D.M. Stocco, B.J. Clark, K.L. Parker, Targeted disruption of the mouse gene encoding steroidogenic acute regulatory protein provides insights into congenital lipoid adrenal hyperplasia, Proc Natl Acad Sci U S A. 94 (1997) 11540-5.

[24] F. Arakane, C.B. Kallen, H. Watari, J.A. Foster, N.B. Sepuri, D. Pain, et al., The mechanism of action of steroidogenic acute regulatory protein (StAR). StAR acts on the outside of mitochondria to stimulate steroidogenesis, J. Biol. Chem. 273 (1998) 16339-16345.

[25] H. Bose, V.R. Lingappa, W.L. Miller, Rapid regulation of steroidogenesis by mitochondrial protein import, Nature. 417 (2002) 87-91.

[26] G. Sasaki, T. Ishii, P. Jeyasuria, Y. Jo, A. Bahat, J. Orly, et al., Complex Role of the Mitochondrial Targeting Signal in the Function of Steroidogenic Acute Regulatory Protein Revealed by Bacterial Artificial Chromosome Transgenesis in Vivo, Molecular Endocrinology. 22 (2008) 951-964.

[27] M.B. Rone, J. Fan, V. Papadopoulos, Cholesterol transport in steroid biosynthesis: Role of protein-protein interactions and implications in disease states, Biochimica et Biophysica Acta (BBA) - Molecular and Cell Biology of Lipids. 1791 (2009) 646-658.

[28] F. Alpy, F. Legueux, L. Bianchetti, C. Tomasetto, [START domaincontaining proteins: a review of their role in lipid transport and exchange], Med Sci (Paris). 25 (2009) 181-91. 
[29] F. Alpy, V.K. Latchumanan, V. Kedinger, A. Janoshazi, C. Thiele, C. Wendling, et al., Functional characterization of the MENTAL domain, J Biol Chem. 280 (2005) 17945-52.

[30] M. Holtta-Vuori, F. Alpy, K. Tanhuanpaa, E. Jokitalo, A.L. Mutka, E. Ikonen, MLN64 is involved in actin-mediated dynamics of late endocytic organelles, Mol Biol Cell. 16 (2005) 3873-86.

[31] A. Liapis, F.W. Chen, J.P. Davies, R. Wang, Y.A. Ioannou, MLN64 Transport to the Late Endosome Is Regulated by Binding to 14-3-3 via a Non-canonical Binding Site, PLoS ONE. 7 (2012) e34424.

[32] M. Zhang, P. Liu, N.K. Dwyer, L.K. Christenson, T. Fujimoto, F. Martinez, et al., MLN64 mediates mobilization of lysosomal cholesterol to steroidogenic mitochondria, J Biol Chem. 277 (2002) 33300-10.

[33] M. Charman, B.E. Kennedy, N. Osborne, B. Karten, MLN64 mediates egress of cholesterol from endosomes to mitochondria in the absence of functional Niemann-Pick Type C1 protein, J. Lipid Res. 51 (2010) 1023-1034.

[34] T. Kishida, I. Kostetskii, Z. Zhang, F. Martinez, P. Liu, S.U. Walkley, et al., Targeted mutation of the MLN64 START domain causes only modest alterations in cellular sterol metabolism, J Biol Chem. 279 (2004) 19276-85.

[35] R.E. Soccio, R.M. Adams, M.J. Romanowski, E. Sehayek, S.K. Burley, J.L. Breslow, The cholesterol-regulated StarD4 gene encodes a StAR-related lipid transfer protein with two closely related homologues, StarD5 and StarD6, Proc Natl Acad Sci U S A. 99 (2002) 6943-8.

[36] D. Rodriguez-Agudo, M. Calderon-Dominguez, S. Ren, D. Marques, K. Redford, M.A. Medina-Torres, et al., Subcellular localization and regulation of StarD4 protein in macrophages and fibroblasts, Biochim. Biophys. Acta. 1811 (2011) 597-606.

[37] J.L. Goldstein, R.A. DeBose-Boyd, M.S. Brown, Protein sensors for membrane sterols, Cell. 124 (2006) 35-46.

[38] T.-Y. Chang, B.-L. Li, C.C.Y. Chang, Y. Urano, Acyl-coenzyme A:cholesterol acyltransferases, Am. J. Physiol. Endocrinol. Metab. 297 (2009) E1-9.

[39] B. Mesmin, N.H. Pipalia, F.W. Lund, T.F. Ramlall, A. Sokolov, D. Eliezer, et al., STARD4 abundance regulates sterol transport and sensing, Mol. Biol. Cell. 22 (2011) 4004-4015.

[40] D. Rodriguez-Agudo, S. Ren, E. Wong, D. Marques, K. Redford, G. Gil, et al., Intracellular cholesterol transporter StarD4 binds free cholesterol and increases cholesteryl ester formation, J. Lipid Res. 49 (2008) 14091419.

[41] B. Mesmin, B. Antonny, G. Drin, Insights into the mechanisms of sterol transport between organelles, Cell. Mol. Life Sci. (2013).

[42] R.E. Soccio, R.M. Adams, K.N. Maxwell, J.L. Breslow, Differential gene regulation of StarD4 and StarD5 cholesterol transfer proteins. Activation of StarD4 by sterol regulatory element-binding protein- 2 and StarD5 by endoplasmic reticulum stress, J Biol Chem. 280 (2005) 194108.

[43] J.J. Riegelhaupt, M.P. Waase, J. Garbarino, D.E. Cruz, J.L. Breslow, Targeted disruption of steroidogenic acute regulatory protein D4 leads to modest weight reduction and minor alterations in lipid metabolism, J. Lipid Res. 51 (2010) 1134-1143.

[44] D. Rodriguez-Agudo, S. Ren, P.B. Hylemon, K. Redford, R. Natarajan, A. Del Castillo, et al., Human StarD5, a cytosolic StAR-related lipid binding protein, J Lipid Res. 46 (2005) 1615-23.

[45] D. Létourneau, A. Lorin, A. Lefebvre, V. Frappier, F. Gaudreault, R. Najmanovich, et al., StAR-related lipid transfer domain protein 5 binds primary bile acids, J. Lipid Res. 53 (2012) 2677-2689.

[46] C. Gomes, S.D. Oh, J.W. Kim, S.Y. Chun, K. Lee, H.B. Kwon, et al., Expression of the putative sterol binding protein Stard6 gene is male germ cell specific, Biol Reprod. 72 (2005) 651-8.

[47] Y. Horibata, H. Sugimoto, StarD7 mediates the intracellular trafficking of phosphatidylcholine to mitochondria, J. Biol. Chem. 285 (2010) 7358-7365.

[48] M.A. Olayioye, S. Vehring, P. Muller, A. Herrmann, J. Schiller, C. Thiele, et al., StarD10, a START domain protein overexpressed in breast cancer, functions as a phospholipid transfer protein, J Biol Chem. 280 (2005) 27436-42.

[49] K.W. Wirtz, Phospholipid transfer proteins, Annu Rev Biochem. 60 (1991) 73-99.

[50] K. Hanada, K. Kumagai, S. Yasuda, Y. Miura, M. Kawano, M. Fukasawa, et al., Molecular machinery for non-vesicular trafficking of ceramide, Nature. 426 (2003) 803-9.

[51] H.W. Kang, J. Wei, D.E. Cohen, PC-TP/StARD2: Of membranes and metabolism, Trends Endocrinol. Metab. 21 (2010) 449-456.

[52] A.P. de Brouwer, J. Westerman, A. Kleinnijenhuis, L.E. Bevers, B. Roelofsen, K.W. Wirtz, Clofibrate-induced relocation of phosphatidylcholine transfer protein to mitochondria in endothelial cells, Exp Cell Res. 274 (2002) 100-11.

[53] K. Kanno, M.K. Wu, D.S. Agate, B.J. Fanelli, N. Wagle, E.F. Scapa, et al., Interacting proteins dictate function of the minimal START domain phosphatidylcholine transfer protein/StarD2, J. Biol. Chem. 282 (2007) 30728-30736.

[54] J. Flores-Martin, V. Rena, S. Angeletti, G. Panzetta-Dutari, S. GentiRaimondi, The Lipid Transfer Protein StarD7: Structure, Function, and Regulation, International Journal of Molecular Sciences. 14 (2013) 6170-6186.

[55] M.A. Olayioye, M. Buchholz, S. Schmid, P. Schöffler, P. Hoffmann, T. Pomorski, Phosphorylation of StarD10 on Serine 284 by Casein Kinase II Modulates Its Lipid Transfer Activity, J. Biol. Chem. 282 (2007) 2249222498.

[56] D. Halter, S. Neumann, S.M. van Dijk, J. Wolthoorn, A.M. de Mazière, O.V. Vieira, et al., Pre- and post-Golgi translocation of glucosylceramide in glycosphingolipid synthesis, J Cell Biol. 179 (2007) 101-115.

[57] K. Kumagai, S. Yasuda, K. Okemoto, M. Nishijima, S. Kobayashi, K. Hanada, CERT mediates intermembrane transfer of various molecular species of ceramides, J Biol Chem. 280 (2005) 6488-95.

[58] K. Hanada, K. Kumagai, N. Tomishige, T. Yamaji, CERT-mediated trafficking of ceramide, Biochim Biophys Acta. 1791 (2009) 684-91.

[59] X. Wang, R.P. Rao, T. Kosakowska-Cholody, M.A. Masood, E. Southon, $H$. Zhang, et al., Mitochondrial degeneration and not apoptosis is the primary cause of embryonic lethality in ceramide transfer protein mutant mice, J. Cell Biol. 184 (2009) 143-158.

[60] M.E. Durkin, B.-Z. Yuan, X. Zhou, D.B. Zimonjic, D.R. Lowy, S.S. Thorgeirsson, et al., DLC-1:a Rho GTPase-activating protein and tumour suppressor, J. Cell. Mol. Med. 11 (2007) 1185-1207.

[61] Y.-C. Liao, S.H. Lo, Deleted in liver cancer-1 (DLC-1): a tumor suppressor not just for liver, Int. J. Biochem. Cell Biol. 40 (2008) 843-847.

[62] D. Lukasik, E. Wilczek, A. Wasiutynski, B. Gornicka, Deleted in liver cancer protein family in human malignancies (Review), Oncol Lett. 2 (2011) 763-768.

[63] D. Zhong, J. Zhang, S. Yang, U.J.K. Soh, J.P. Buschdorf, Y.T. Zhou, et al., The SAM domain of the RhoGAP DLC1 binds EF1A1 to regulate cell migration, J. Cell. Sci. 122 (2009) 414-424.

[64] Y.P. Ching, C.M. Wong, S.F. Chan, T.H. Leung, D.C. Ng, D.Y. Jin, et al., Deleted in liver cancer (DLC) 2 encodes a RhoGAP protein with growth suppressor function and is underexpressed in hepatocellular carcinoma, J Biol Chem. 278 (2003) 10824-30.

[65] K. Kawai, M. Kiyota, J. Seike, Y. Deki, H. Yagisawa, START-GAP3/DLC3 is a GAP for RhoA and Cdc42 and is localized in focal adhesions regulating cell morphology, Biochem Biophys Res Commun. 364 (2007) 783-9.

[66] Y. Homma, Y. Emori, A dual functional signal mediator showing RhoGAP and phospholipase C-delta stimulating activities, EMBO J. 14 (1995) 286-291.

[67] K.D. Healy, L. Hodgson, T.-Y. Kim, A. Shutes, S. Maddileti, R.L. Juliano, et al., DLC-1 suppresses non-small cell lung cancer growth and invasion by RhoGAP-dependent and independent mechanisms, Mol. Carcinog. 47 (2008) 326-337.

[68] C.M. Wong, J.M. Lee, Y.P. Ching, D.Y. Jin, I.O. Ng, Genetic and epigenetic alterations of DLC-1 gene in hepatocellular carcinoma, Cancer Res. 63 (2003) 7646-51.

[69] M. Sekimata, Y. Kabuyama, Y. Emori, Y. Homma, Morphological changes and detachment of adherent cells induced by p122, a GTPaseactivating protein for Rho, J. Biol. Chem. 274 (1999) 17757-17762.

[70] K. Kawai, M. Yamaga, Y. Iwamae, M. Kiyota, H. Kamata, H. Hirata, et al., A PLCdelta1-binding protein, p122RhoGAP, is localized in focal adhesions, Biochem. Soc. Trans. 32 (2004) 1107-1109.

[71] K. Kawai, J. Seike, T. lino, M. Kiyota, Y. Iwamae, H. Nishitani, et al., START-GAP2/DLC2 is localized in focal adhesions via its $\mathrm{N}$-terminal region, Biochem. Biophys. Res. Commun. 380 (2009) 736-741.

[72] Y.-C. Liao, L. Si, R.W. deVere White, S.H. Lo, The phosphotyrosineindependent interaction of DLC-1 and the $\mathrm{SH} 2$ domain of cten regulates focal adhesion localization and growth suppression activity of DLC-1, J. Cell Biol. 176 (2007) 43-49.

[73] K. Dai, S. Liao, J. Zhang, X. Zhang, X. Tu, Solution structure of tensin2 $\mathrm{SH} 2$ domain and its phosphotyrosine-independent interaction with DLC-1, PLoS ONE. 6 (2011) e21965.

[74] T.O. Yau, T.H.Y. Leung, S. Lam, O.F. Cheung, E.K.K. Tung, P.L. Khong, et al., Deleted in Liver Cancer 2 (DLC2) Was Dispensable for Development and Its Deficiency Did Not Aggravate Hepatocarcinogenesis, PLoS ONE. 4 (2009) e6566. 
[75] K.M. Petzold, H. Naumann, F.M. Spagnoli, Rho signalling restriction by the RhoGAP Stard13 integrates growth and morphogenesis in the pancreas, Development. 140 (2013) 126-135.

[76] M.E. Durkin, M.R. Avner, C.G. Huh, B.Z. Yuan, S.S. Thorgeirsson, N.C. Popescu, DLC-1, a Rho GTPase-activating protein with tumor suppressor function, is essential for embryonic development, FEBS Lett. 579 (2005) 1191-6.

[77] G.M. Hatch, Y. Gu, F.Y. Xu, J. Cizeau, S. Neumann, J.-S. Park, et al., StARD13(Dlc-2) RhoGap mediates ceramide activation of phosphatidylglycerolphosphate synthase and drug response in Chinese hamster ovary cells, Mol. Biol. Cell. 19 (2008) 1083-1092.

[78] B. Kirkby, N. Roman, B. Kobe, S. Kellie, J.K. Forwood, Functional and structural properties of mammalian acyl-coenzyme A thioesterases, Prog. Lipid Res. 49 (2010) 366-377.

[79] A.-G. Thorsell, W.H. Lee, C. Persson, M.I. Siponen, M. Nilsson, R.D. Busam, et al., Comparative Structural Analysis of Lipid Binding START Domains, PLoS ONE. 6 (2011) e19521.

[80] S. Han, D.E. Cohen, Functional characterization of thioesterase superfamily member $1 /$ Acyl-CoA thioesterase 11: implications for metabolic regulation, J. Lipid Res. 53 (2012) 2620-2631.

[81] S.H. Adams, C. Chui, S.L. Schilbach, X.X. Yu, A.D. Goddard, J.C. Grimaldi, et al., BFIT, a unique acyl-CoA thioesterase induced in thermogenic brown adipose tissue: cloning, organization of the human gene and assessment of a potential link to obesity, Biochem J. 360 (2001) 13542.

[82] D. Chen, J. Latham, H. Zhao, M. Bisoffi, J. Farelli, D. Dunaway-Mariano, Human Brown Fat Inducible Thioesterase Variant 2 Cellular Localization and Catalytic Function, Biochemistry. 51 (2012) 6990-6999.

[83] N. Suematsu, K. Okamoto, K. Shibata, Y. Nakanishi, F. Isohashi, Molecular cloning and functional expression of rat liver cytosolic acetylCoA hydrolase, Eur. J. Biochem. 268 (2001) 2700-2709.

[84] N. Suematsu, F. Isohashi, Molecular cloning and functional expression of human cytosolic acetyl-CoA hydrolase, Acta Biochim Pol. 53 (2006) 553-61.

[85] J.Z. Torres, M.K. Summers, D. Peterson, M.J. Brauer, J. Lee, S. Senese, et al., The STARD9/Kif16a kinesin associates with mitotic microtubules and regulates spindle pole assembly, Cell. 147 (2011) 1309-1323.

[86] H. Miki, Y. Okada, N. Hirokawa, Analysis of the kinesin superfamily: insights into structure and function, Trends in Cell Biology. 15 (2005) 467-476.

[87] N. Kudo, K. Kumagai, N. Tomishige, T. Yamaji, S. Wakatsuki, M. Nishijima, et al., Structural basis for specific lipid recognition by CERT responsible for nonvesicular trafficking of ceramide, Proc Natl Acad Sci U S A. 105 (2008) 488-93.

[88] H.S. Bose, R.M. Whittal, M.A. Baldwin, W.L. Miller, The active form of the steroidogenic acute regulatory protein, StAR, appears to be a molten globule, Proc Natl Acad Sci U S A. 96 (1999) 7250-5.

[89] B.Y. Baker, D.C. Yaworsky, W.L. Miller, A pH-dependent molten globule transition is required for activity of the steroidogenic acute regulatory protein, StAR, J Biol Chem. 280 (2005) 41753-60.

[90] P. Lavigne, R. Najmanivich, J.-G. LeHoux, Mammalian StAR-Related Lipid Transfer (START) Domains with Specificity for Cholesterol: Structural Conservation and Mechanism of Reversible Binding, in: J.R. Harris (Ed.), Cholesterol Binding and Cholesterol Transport Proteins:, Springer Netherlands, 2010: pp. 425-437.

[91] M. Murcia, J.D. Faraldo-Gomez, F.R. Maxfield, B. Roux, Modeling the structure of the StART domains of MLN64 and StAR proteins in complex with cholesterol, J Lipid Res. 47 (2006) 2614-30.

[92] K. Schrick, D. Nguyen, W.M. Karlowski, K.F. Mayer, START lipid/sterolbinding domains are amplified in plants and are predominantly associated with homeodomain transcription factors, Genome Biol. 5 (2004) R41.

[93] L. Feng, W.W. Chan, S.L. Roderick, D.E. Cohen, High-level expression and mutagenesis of recombinant human phosphatidylcholine transfer protein using a synthetic gene: evidence for a C-terminal membrane binding domain, Biochemistry. 39 (2000) 15399-15409.

[94] T. Levine, C. Loewen, Inter-organelle membrane contact sites: through a glass, darkly, Curr Opin Cell Biol. 18 (2006) 371-8.

[95] A. Toulmay, W.A. Prinz, Lipid transfer and signaling at organelle contact sites: the tip of the iceberg, Curr Opin Cell Biol. 23 (2011) 458-63.

[96] T.P. Levine, S. Munro, Targeting of Golgi-specific pleckstrin homology domains involves both Ptdlns 4-kinase-dependent and -independent components, Curr Biol. 12 (2002) 695-704.

[97] C.J. Loewen, A. Roy, T.P. Levine, A conserved ER targeting motif in three families of lipid binding proteins and in Opilp binds VAP, Embo J. 22 (2003) 2025-35.
[98] S. Munro, Cell biology: earthworms and lipid couriers, Nature. 426 (2003) 775-6.

[99] M. de Saint-Jean, V. Delfosse, D. Douguet, G. Chicanne, B. Payrastre, W. Bourguet, et al., Osh4p exchanges sterols for phosphatidylinositol 4phosphate between lipid bilayers, J Cell Biol. 195 (2011) 965-78.

[100] K. Hanada, Intracellular trafficking of ceramide by ceramide transfer protein, Proceedings of the Japan Academy, Series B. 86 (2010) 426437.

[101] M. Ito, Y. Yamanashi, Y. Toyoda, H. Izumi-Nakaseko, S. Oda, A. Sugiyama, et al., Disruption of Stard10 gene alters the PPAR $\alpha$-mediated bile acid homeostasis, Biochimica et Biophysica Acta (BBA) - Molecular and Cell Biology of Lipids. 1831 (2013) 459-468.

[102] A. van Helvoort, A. de Brouwer, R. Ottenhoff, J.F. Brouwers, J. Wijnholds, J.H. Beijnen, et al., Mice without phosphatidylcholine transfer protein have no defects in the secretion of phosphatidylcholine into bile or into lung airspaces, Proc Natl Acad Sci U S A. 96 (1999) 11501-6.

[103] H.W. Kang, S. Ribich, B.W. Kim, S.J. Hagen, A.C. Bianco, D.E. Cohen, Mice lacking Pctp /StarD2 exhibit increased adaptive thermogenesis and enlarged mitochondria in brown adipose tissue, J. Lipid Res. 50 (2009) 2212-2221.

[104] E.F. Scapa, A. Pocai, M.K. Wu, R. Gutierrez-Juarez, L. Glenz, K. Kanno, et al., Regulation of energy substrate utilization and hepatic insulin sensitivity by phosphatidylcholine transfer protein/StarD2, FASEB J. 22 (2008) 2579-2590.

[105] Y. Zhang, Y. Li, M.W. Niepel, Y. Kawano, S. Han, S. Liu, et al., Targeted deletion of thioesterase superfamily member 1 promotes energy expenditure and protects against obesity and insulin resistance, Proc. Natl. Acad. Sci. U.S.A. 109 (2012) 5417-5422.

[106] S.R. King, A. Bhangoo, D.M. Stocco, Functional and physiological consequences of StAR deficiency: role in lipoid congenital adrenal hyperplasia, Endocr Dev. 20 (2011) 47-53.

[107] C. Moog-Lutz, C. Tomasetto, C.H. Regnier, C. Wendling, Y. Lutz, D. Muller, et al., MLN64 exhibits homology with the steroidogenic acute regulatory protein (STAR) and is over-expressed in human breast carcinomas, Int J Cancer. 71 (1997) 183-91.

[108] M.A. Olayioye, P. Hoffmann, T. Pomorski, J. Armes, R.J. Simpson, B.E. Kemp, et al., The phosphoprotein StarD10 is overexpressed in breast cancer and cooperates with ErbB receptors in cellular transformation, Cancer Res. 64 (2004) 3538-44.

[109] K.K. Sahlberg, V. Hongisto, H. Edgren, R. Mäkelä, K. Hellström, E.U. Due, et al., The HER2 amplicon includes several genes required for the growth and survival of HER2 positive breast cancer cells, Molecular Oncology. (2012).

[110] J. Kao, J.R. Pollack, RNA interference-based functional dissection of the $17 q 12$ amplicon in breast cancer reveals contribution of coamplified genes, Genes Chromosomes Cancer. 45 (2006) 761-769.

111] N.C. Murphy, A.V. Biankin, E.K.A. Millar, C.M. McNeil, S.A. O’Toole, D. Segara, et al., Loss of STARD10 expression identifies a group of poor prognosis breast cancers independent of HER2/Neu and triple negative status, International Journal of Cancer. 126 (2010) 1445-1453.

[112] G. Vetter, A. Saumet, M. Moes, L. Vallar, A.L. Béchec, C. Laurini, et al., miR-661 expression in SNAI1-induced epithelial to mesenchymal transition contributes to breast cancer cell invasion by targeting Nectin1 and StarD10 messengers, Oncogene. 29 (2010) 4436-4448.

[113] B.Z. Yuan, M.J. Miller, C.L. Keck, D.B. Zimonjic, S.S. Thorgeirsson, N.C. Popescu, Cloning, characterization, and chromosomal localization of a gene frequently deleted in human liver cancer (DLC-1) homologous to rat RhoGAP, Cancer Res. 58 (1998) 2196-9.

[114] D.B. Zimonjic, N.C. Popescu, Role of DLC1 tumor suppressor gene and MYC oncogene in pathogenesis of human hepatocellular carcinoma: potential prospects for combined targeted therapeutics (review), Int. J. Oncol. 41 (2012) 393-406.

[115] B.Z. Yuan, M.E. Durkin, N.C. Popescu, Promoter hypermethylation of DLC-1, a candidate tumor suppressor gene, in several common human cancers, Cancer Genet Cytogenet. 140 (2003) 113-7.

[116] M. Plaumann, S. Seitz, R. Frege, L. Estevez-Schwarz, S. Scherneck, Analysis of DLC-1 expression in human breast cancer, J Cancer Res Clin Oncol. 129 (2003) 349-54.

[117] B.Z. Yuan, X. Zhou, M.E. Durkin, D.B. Zimonjic, K. Gumundsdottir, J.E. Eyfjord, et al., DLC-1 gene inhibits human breast cancer cell growth and in vivo tumorigenicity, Oncogene. 22 (2003) 445-50.

[118] K. Banaudha, M. Kaliszewski, T. Korolnek, L. Florea, M.L. Yeung, K.-T. Jeang, et al., MicroRNA silencing of tumor suppressor DLC-1 promotes efficient hepatitis $C$ virus replication in primary human hepatocytes, Hepatology. 53 (2011) 53-61. 
[119] B.Z. Yuan, A.M. Jefferson, K.T. Baldwin, S.S. Thorgeirsson, N.C. Popescu, S.H. Reynolds, DLC-1 operates as a tumor suppressor gene in human non-small cell lung carcinomas, Oncogene. 23 (2004) 1405-11.

[120] X. Zhou, S.S. Thorgeirsson, N.C. Popescu, Restoration of DLC-1 gene expression induces apoptosis and inhibits both cell growth and tumorigenicity in human hepatocellular carcinoma cells, Oncogene. 23 (2004) 1308-13.

[121] S. Goodison, J. Yuan, D. Sloan, R. Kim, C. Li, N.C. Popescu, et al., The RhoGAP protein DLC-1 functions as a metastasis suppressor in breast cancer cells, Cancer Res. 65 (2005) 6042-6053.

[122] C.-M. Wong, J.W.-P. Yam, Y.-P. Ching, T.-O. Yau, T.H.-Y. Leung, D.-Y. Jin, et al., Rho GTPase-activating protein deleted in liver cancer suppresses cell proliferation and invasion in hepatocellular carcinoma, Cancer Res. 65 (2005) 8861-8868.

[123] V. Ullmannova, N.C. Popescu, Expression profile of the tumor suppressor genes DLC-1 and DLC-2 in solid tumors, Int. J. Oncol. 29 (2006) 1127-1132.

[124] M.E. Durkin, V. Ullmannova, M. Guan, N.C. Popescu, Deleted in liver cancer 3 (DLC-3), a novel Rho GTPase-activating protein, is downregulated in cancer and inhibits tumor cell growth, Oncogene. 26 (2007) 4580-4589.

[125] A. Raya, F. Revert, S. Navarro, J. Saus, Characterization of a novel type of serine/threonine kinase that specifically phosphorylates the human goodpasture antigen, J Biol Chem. 274 (1999) 12642-9.

[126] F. Revert, R. Merino, C. Monteagudo, J. Macias, A. Peydro, J. Alcacer, et al., Increased Goodpasture antigen-binding protein expression induces type IV collagen disorganization and deposit of immunoglobulin A in glomerular basement membrane, Am J Pathol. 171 (2007) 141930.
127] I. Derré, R. Swiss, H. Agaisse, The Lipid Transfer Protein CERT Interacts with the Chlamydia Inclusion Protein IncD and Participates to ER-Chlamydia Inclusion Membrane Contact Sites, PLoS Pathog. 7 (2011) e1002092.

128] C.A. Elwell, S. Jiang, J.H. Kim, A. Lee, T. Wittmann, K. Hanada, et al., Chlamydia trachomatis Co-opts GBF1 and CERT to Acquire Host Sphingomyelin for Distinct Roles during Intracellular Development, PLoS Pathog. 7 (2011) e1002198.

[129] C. Swanton, M. Marani, O. Pardo, P.H. Warne, G. Kelly, E. Sahai, et al., Regulators of mitotic arrest and ceramide metabolism are determinants of sensitivity to paclitaxel and other chemotherapeutic drugs, Cancer Cell. 11 (2007) 498-512.

[130] A.J.X. Lee, R. Roylance, J. Sander, P. Gorman, D. Endesfelder, M. Kschischo, et al., CERT depletion predicts chemotherapy benefit and mediates cytotoxic and polyploid-specific cancer cell death through autophagy induction, The Journal of Pathology. 226 (2012) 482-494.

[131] S. Yasuda, H. Kitagawa, M. Ueno, H. Ishitani, M. Fukasawa, M. Nishijima, et al., A Novel Inhibitor of Ceramide Trafficking from the Endoplasmic Reticulum to the Site of Sphingomyelin Synthesis, J. Biol. Chem. 276 (2001) 43994-44002.

[132] F. Hullin-Matsuda, N. Tomishige, S. Sakai, R. Ishitsuka, K. Ishii, A. Makino, et al., Limonoid compounds inhibit sphingomyelin biosynthesis by preventing CERT protein-dependent extraction of ceramides from the endoplasmic reticulum, J. Biol. Chem. 287 (2012) 24397-24411.

[133] F. Alpy, A. Rousseau, Y. Schwab, F. Legueux, I. Stoll, C. Wendling, C. Spiegelhalter, P. Kessler, C. Mathelin, M.C. Rio, T.P. Levine, C. Tomasetto, STARD3/STARD3NL and VAP make a novel molecular tether between late endosomes and the ER, J. Cell. Sci. 126, (2013) 5500-5512. 